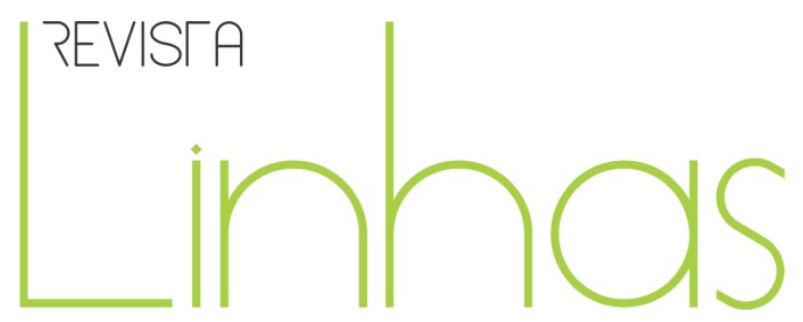

\title{
O currículo vivido por alunos com deficiência na Universidade Federal do Pará: implicações para a educação inclusiva no ensino superior $^{1}$
}

\begin{abstract}
Resumo
Este artigo objetivou conhecer e analisar a perspectiva dos alunos com deficiência regularmente matriculados na Universidade Federal do Pará (UFPA) sobre o currículo vivido em seus cursos de graduação. Para tanto, buscamos conhecer essas vivências curriculares, pensando quais influências essas experiências podem exercer sobre a permanência e a conclusão dos cursos de graduação por esses alunos. A metodologia ancorou-se no paradigma qualitativo de pesquisa, seguindo a perspectiva materialista-histórica e dialética. Contou com uma revisão bibliográfica e com uma pesquisa de campo, por meio da aplicação de uma entrevista estruturada a cinco alunos com deficiência regularmente matriculados na UFPA. A análise dos dados foi realizada por meio da técnica de Análise do Conteúdo. Os resultados apontaram questões concernentes a entraves na vivência dos currículos de seus respectivos cursos de graduação devido à falta de apoio pedagógico e de recursos tecnológicos suficientes, bem como devido à falta de planejamento quanto aos elementos do processo de ensino e aprendizagem como avaliação, metodologias e recursos didáticos. Consideramos que conhecer essas vivências nos permitiu perceber lacunas e necessidades que devemos atentar para a materialização de práticas inclusivas no ensino superior.
\end{abstract}

Palavras-chave: Currículos; Ensino Superior-Pará; Estudantes com deficiência; Universidade Federal do Pará.

\section{Débora Ribeiro da Silva Campos} Folha

Mestre em Educação pela

Universidade Federal do Pará UFPA - Brasil

todeboracampos@gmail.com

\section{Genylton Odilon Rêgo da Rocha \\ Doutor em Geografia pela \\ Universidade de São Paulo - USP - Brasil \\ genylton@gmail.com}

\footnotetext{
Para citar este artigo:

FOLHA, Débora Ribeiro da Silva Campos; ROCHA, Genylton Odilon Rêgo da. O currículo vivido por alunos com deficiência na Universidade Federal do Pará: implicações para a educação inclusiva no ensino superior. Revista Linhas. Florianópolis, v. 15, n. 29, p. 438-462, jul./dez. 2014.
}

DOI: 10.5965/1984723815292014438

http://dx.doi.org/10.5965/1984723815292014438

\footnotetext{
${ }^{1}$ Texto referente a recorte de dissertação de mestrado pelo Programa de Pós-Graduação em Educação do Instituto de Educação da Universidade Federal do Pará (PPGED/ICED/UFPA), com financiamento do Conselho Nacional de Desenvolvimento Científico e Tecnológico (CNPq).
} 


\title{
Curriculum experienced by students with deficiency in Federal University of Pará: implications for the inclusive education in college
}

\begin{abstract}
This article aimed to know and analyse the perspective of students with deficiency regularly enrolled in Federal University of Pará (UFPA) about the curriculum experienced in their graduation courses. For so, we looked for knowing those curricular experiences, thinking about what influences they can exert over the permanence and the conclusion of the graduation courses by those students. The methodology was anchored in the qualitative research paradigm, following a materialist-historical and dialectical perspective. It had a bibliographic revision and a field research, by the application of a structured interview to five students with deficiency regularly enrolled to UFPA. The data analysis was made by the technique of Content Analysis. The results indicated matters related to obstacles in the experience of the curriculum of their respective graduation courses, due to the lack of pedagogical support and sufficient technological resources, as well as the lack of planning about the elements of teaching and learning such as evaluation, methodologies and didactical resources. We consider that knowing those experiences allowed us to perceive lacks and necessities that we need to attend to, in order to materialize inclusive practices in college.
\end{abstract}

Keywords: Curriculum; Higher Education-Pará; Students with disability; Federal University of Pará. 


\section{Notas introdutórias}

O presente artigo corresponde a recorte de dissertação de Mestrado Acadêmico do Programa de Pós-Graduação em Educação do Instituto de Ciências da Educação da Universidade Federal do Pará (PPGED/ICED/UFPA), bem como a uma das produções do Grupo de Estudos e Pesquisa sobre Currículo e Formação de Professores na Perspectiva da Inclusão, vinculado ao Programa supracitado (INCLUDERE/UFPA). O INCLUDERE tem como um de seus principais eixos de estudo e pesquisa a temática da Educação Inclusiva tanto a respeito da formação de professores nesse contexto, quanto a respeito da implementação de práticas efetivamente inclusivas.

No contexto dos debates e pesquisas realizados por este Grupo, este estudo se volta para a educação propiciada pela Universidade aos alunos com deficiência, algo que não fazia parte, até então, das pesquisas desenvolvidas pelo grupo. Essa temática nos despertou inquietações a respeito de como os alunos com deficiência vivenciavam as práticas curriculares a partir dos currículos de seus cursos de graduação.

Consideramos que havia um silêncio a respeito desse assunto, que se mostra carente de estudos e pesquisas, visto que, no movimento de delimitação deste objeto de estudo, realizamos um levantamento bibliográfico no Banco de Teses e Dissertações da Coordenação de Aperfeiçoamento de Pessoal de Nível Superior (CAPES), o qual identificou, 72 trabalhos sobre a temática. Porém, destes 72 trabalhos, apenas sete se dispuseram a estudar a educação inclusiva no ensino superior sob a perspectiva do aluno com deficiência. E nenhum destes, foi realizado na Região Norte do Brasil.

Constatamos, assim, a necessidade de conhecer e compreender como vem se dando a educação inclusiva nas universidades, especificamente na Universidade Federal do Pará, a qual não é mencionada em nenhuma pesquisa, a partir da concepção dos alunos com deficiência, vislumbrando achados indispensáveis para a consolidação da inclusão nessa Instituição.

O Censo mais recente realizado no ano de 2010 pelo Instituto Brasileiro de Geografia e Estatística (IBGE), evidenciou que, no Brasil, 12.777.207 pessoas declararam 
possuir pelo menos um tipo de deficiência severa, representando 6,7\% da população total. Esse Censo classificou, no questionário da amostra, as deficiências visual, auditiva, motora e mental. Para as três primeiras, foram diferenciados, ainda, os graus de severidade: "alguma dificuldade", "grande dificuldade" e "não consegue de modo algum". As pessoas agrupadas na categoria deficiência severa são as que declararam, para um tipo ou mais de deficiência, as opções "grande dificuldade" ou "não consegue de modo algum", além daquelas que declararam possuir deficiência mental (IBGE, 2011).

A deficiência visual severa foi a que mais incidiu sobre a população: em 2010, 3,5\% das pessoas declararam possuir grande dificuldade ou nenhuma capacidade de enxergar. Em seguida, apareceu a deficiência motora severa, atingindo, em $2010,2,3 \%$ das pessoas. O percentual de pessoas que declararam possuir deficiência auditiva severa foi de 1,1\% e o das que declararam ter deficiência mental foi de 1,4\% (IBGE, 2011, s.n.).

Conforme a pesquisa mais recente do Ministério da Educação (BRASIL, 2006), a população com deficiência na faixa etária de 18 a 24 anos matriculada no ensino regular no Brasil (supõe-se que o ensino superior esteja nessa estatística, embora saibamos que nem sempre a pessoa com deficiência chega ao ensino superior nessa faixa etária) era de apenas 1.682.760 pessoas. Em consonância com essas estatísticas, data do ano de 20050 início dos investimentos na educação superior para garantir a inclusão de alunos com deficiência (BRASIL, 2005).

Os resultados da pesquisa de Pessini, Silva e Silva (2007) revelam que as pessoas com deficiência enfrentam muito mais dificuldades relacionadas aos aspectos psicopedagógicos e psicossociais do que aos ambientais e estruturais. Com base nisso, pensamos que a questão da permanência e conclusão do ensino superior pelo aluno com deficiência é transversalizada e influenciada por vários aspectos, tais como a acessibilidade física/arquitetônica, os fatores socioeconômicos e os fatores curriculares. Inferimos, portanto, que os alunos inseridos nesse processo de inclusão na Universidade apresentam representações acerca desses aspectos. 
Arroyo (2011) considera o campo do currículo como um território de disputa, poder e conflito. Já Sacristán (2000), o considera como: um documento historicamente configurado; uma seleção de conteúdos selecionados a partir de uma determinação visão política e de acordo com os interesses de quem o seleciona; um instrumento de invenção e de ação social; o cruzamento de práticas diversas; a expressão de várias determinações políticas para a prática escolar; um instrumento de seleção de cultura; e expressão de determinações sociais. Assim, adotamos o conceito de currículo como "a construção social que preenche a escolaridade de conteúdos e orientações" (SACRISTÁN, 2000, p. 20), caracterizado por um "conjunto temático abordável interdisciplinarmente, que serve de núcleo de aproximação para outros muitos conhecimentos e contribuições sobre a educação" (p. 29).

Partindo destas concepções de currículo enquanto "projeto cultural elaborado sob chaves pedagógicas" (SACRISTÁN, 1998, p. 84), este pode ser compreendido como um aglomerado de códigos direcionados a modelar as práticas educacionais, de modo que necessitam estar de acordo com os contextos de sua formulação e realização. A elaboração destes códigos, muitas vezes, se dá exteriormente à prática nestes contextos, o que faz com que o currículo venha a ser um mero conglomerado de táticas apoiadas na falta de preparo docente e na imposição de esquemas técnicos sobre suas práticas (SACRISTÁN, 1998).

Conforme Alcoba (s.d.), os currículos dos cursos de graduação são geralmente muito densos e direcionados dentro da especialidade escolhida, subtraindo do aluno o tempo necessário para estudar e refletir sobre o que faz e ouve durante as aulas. Há, dessa forma, uma restrição à sua formação como cidadão, a qual deveria proporcionar um olhar mais amplo, crítico e integrado sobre o mundo e sua própria atividade. Em pesquisa que este autor realizou junto a professores universitários, os mesmos referiram que

o currículo "devia ter certa flexibilidade" porque ainda "é muito engessado" ou que o chamamos "grade curricular porque é uma prisão mesmo", fruto de uma "herança paternalista e autoritária." Pensam que "os currículos deviam reduzir-se a um mínimo", deixando "o aluno compor a formação dele" (ALCOBA, [20--]., p. 11). 
Centramos nosso estudo na Universidade Federal do Pará, devido à mesma ser a instituição pública de ensino superior mais antiga e consolidada da região, sendo a que oferece o maior número de vagas nos vestibulares. Com base em dados da Pró-Reitoria de Ensino e Graduação da Universidade Federal do Pará, essa Universidade é uma das maiores e mais importantes instituições da Amazônia, congregando uma comunidade composta por mais de 50 mil pessoas, assim distribuídas: 2.368 professores, incluindo efetivos do ensino superior, efetivos do ensino básico, substitutos e visitantes; 2.337 servidores técnico-administrativos; 6.861 alunos de cursos de pós-graduação, sendo 2.457 estudantes de cursos de pós-graduação stricto sensu (mestrado e doutorado); 31.174 alunos matriculados nos cursos de graduação, 20.460 na capital e 10.714 no interior do Estado; 1.851 alunos do ensino fundamental e médio, da Escola de Aplicação; 2.916 alunos dos Cursos Livres oferecidos pelo Instituto de Letras e Comunicação Social (ILC), Instituto de Ciência da Arte (ICA), Escola de Teatro e Dança, Escola de Música e Casa de estudos Germânicos, além de 664 alunos dos cursos técnico-profissionalizantes do ICA. Oferece 338 cursos de graduação e 39 programas de pós-graduação, com 38 cursos de mestrado e 17 de doutorado (disponível em www.ufpa.br).

Devido essa complexa estrutura consolidada e historicamente reconhecida, concebemos que desenvolver a presente pesquisa na UFPA nos permitiria constituir um panorama acerca da educação inclusiva no ensino superior em Belém.

Assim, o presente artigo objetivou conhecer a perspectiva dos alunos com deficiência regularmente matriculados na UFPA sobre o currículo vivido em seus cursos de graduação, com base nas seguintes questões norteadoras: Quais as vivências curriculares dos alunos com deficiência regularmente matriculados na Universidade Federal do Pará? Que influências essas experiências exercem sobre a permanência e a conclusão dos cursos de graduação por esses alunos? 


\section{O percurso metodológico}

Para este estudo, elegemos um percurso metodológico ancorado no paradigma qualitativo de pesquisa, norteado pelo método materialista histórico, o qual penetra no mundo dos fenômenos, analisando-o através de sua ação recíproca, da contradição inerente ao fenômeno e da mudança dialética que ocorre na natureza e na sociedade. Pires (1997) apresenta esse método como uma das formas de interpretar a realidade, assim como a realidade educacional. Para esta autora, Marx pensou o materialismo histórico-dialético considerando o caráter material e histórico do homem e a dialética. $\mathrm{O}$ caráter material dos homens é expresso por sua organização na sociedade para a produção e a reprodução da vida material, ou seja, as atividades humanas giram em torno dessa vida material. O caráter histórico é preciso ser considerado devido às diversas formas de organização que, historicamente, as sociedades assumiram. E a dialética corresponde a uma tentativa de superação da dicotomia entre sujeito e objeto, evidenciando as contradições presentes na realidade social.

O tipo da pesquisa ora relatada correspondeu a um estudo de caso históricoorganizacional, o qual, segundo Triviños (1987; 2011) enfoca um aspecto de uma determinada organização, uma parte do todo que corresponde a esta organização. Nesse sentido, a preocupação desse tipo de pesquisa é retratar a complexidade de uma situação particular, porém focalizando o problema em seu aspecto total dentro de uma organização ampla e complexa, ou seja, a análise acerca das representações dos alunos com deficiência sobre os currículos de seus cursos de graduação na UFPA permitirá vislumbrar como vem se dando a inclusão na Universidade pública paraense.

Dessa forma, o estudo de caso que ora apresentamos lançou mão de revisão bibliográfica e de pesquisa de campo. A revisão bibliográfica foi essencial para reunir referências pertinentes para a fundamentação de nosso objeto de estudo. E, para a pesquisa de campo, utilizamos a entrevista estruturada, como técnica de coleta de dados.

A entrevista estruturada é definida por Severino (2007) como aquela na qual as questões são direcionadas e previamente estabelecidas, com determinada articulação 
interna, pois, "com questões bem diretivas, obtém, do universo de sujeitos, respostas também mais facilmente categorizáveis, sendo assim muito útil para o desenvolvimento de levantamentos sociais" (SEVERINO, 2007, p. 125).

A respeito das etapas de execução da pesquisa, a primeira etapa constituiu da revisão bibliográfica, objetivando embasar o estudo, com ênfase na história da educação especial e inclusiva e nos movimentos sociais de luta por direitos na educação de pessoas com deficiência. Nessa etapa, foram analisadas as dissertações e teses referentes a essa temática, bem como artigos e livros que se mostrassem importantes para a compreensão da realidade a ser estudada e subsidiassem a elaboração das seções teóricas.

Ao mesmo tempo, foi realizada busca ativa dos alunos com deficiência regularmente matriculados na Universidade Federal do Pará, no sentido de constituir a amostra desta pesquisa, apresentando-Ihes o Termo de Consentimento Livre e Esclarecido (TCLE). Todos os alunos que compuseram a amostra foram convidados a participar da pesquisa. Do mesmo modo, foram seguidos os preceitos da Declaração de Helsinque e o Código de Nuremberg e respeitadas as normas de pesquisa envolvendo seres humanos (Res. CNS 196/96).

Na segunda etapa foi realizada a coleta de dados, a partir da aplicação de entrevistas aos sujeitos de pesquisa. A seleção destes foi feita por meio de busca ativa nos cursos de graduação da UFPA, bem como por indicação. Assim, foram eleitos como sujeitos de pesquisa 05 (cinco) alunos com deficiência (física e visual), regularmente matriculados na Universidade Federal do Pará.

Como critérios de inclusão, estavam aptos a ser sujeitos de pesquisa alunos que estivessem cursando curso e graduação presencial na UFPA até o ano de 2012 (dois mil e doze), que aceitassem participar da pesquisa, consentindo essa participação por meio da assinatura do TCLE. Como critérios de exclusão, foram excluídos da amostra alunos que não se enquadrassem nos critérios anteriormente citados.

Todos os sujeitos de pesquisa foram entrevistados nas dependências da UFPA, em dia e horário previamente agendados, de acordo com a disponibilidade dos mesmos. Todas as entrevistas foram gravadas e posteriormente transcritas. 
Para a organização e análise do material de investigação, foi utilizado o método de Análise de Conteúdo, que, para Minayo et al (1994) é a principal forma de tratar os dados em pesquisas qualitativas. Esse método é definido por Bardin (1979) como um conjunto de técnicas de análise da comunicação, que visam inferir conhecimentos relativos às mensagens emitidas pelos sujeitos, através de procedimentos sistemáticos de descrição de conteúdos mencionados.

Com base na releitura que Franco (2008) fez de Bardin (1979), a Análise do Conteúdo é um procedimento de pesquisa que pode ser utilizado no âmbito de uma abordagem metodológica crítica e apoiada em uma concepção de ciência que reconhece o papel ativo do sujeito frente às transformações sociais.

A autora esclarece que, pelo fato da Análise do Conteúdo se assentar nos pressupostos de uma concepção crítica e dinâmica da linguagem, compreende esta como "uma construção real de toda a sociedade e como a expressão da existência humana que, em diferentes momentos históricos, elabora e desenvolve representações sociais no dinamismo interacional que se estabelece entre linguagem, pensamento e ação" (FRANCO, 2008, p. 13).

Assim, a Análise do Conteúdo se mostrou uma técnica de análise de dados adequada para a presente pesquisa, visto que "esse procedimento tende a valorizar o material a ser analisado, especialmente se a interpretação do conteúdo 'latente' estipular, como parâmetros, os contextos individuais, sociais e históricos no quais foram produzidos" (FRANCO, 2008, p. 16).

Assim, a partir destas falas dos entrevistados, foram criadas categorias para análise dos dados, fundamentadas nos referenciais teórico-metodológicos eleitos, explicitadas a seguir. 

educação inclusiva na Universidade Federal do Pará

Entendemos que o currículo corresponde tanto a uma questão de conhecimento, quanto a uma questão de identidade. Assim como Goodson (2011), compreendemos a importância de ultrapassar o currículo escrito, o formal, prescritivo e padronizado, para identificar as representações fruto da vivência do mesmo, na prática educacional em sala de aula na Universidade, à luz do paradigma materialista-histórico e dialético de pesquisa, sob a perspectiva da educação inclusiva. Para tanto, assumimos a perspectiva da Teoria Crítica do Currículo, a qual

é um movimento de constante problematização e questionamento. Nesse processo, novas questões e temas vêm-se incorporar àqueles que, desde o seu início, estiveram no centro de sua preocupação. É isso que constitui sua vitalidade e seu potencial (MOREIRA; SILVA, 2011, p. 44).

Assim, defendemos a incorporação da temática da educação inclusiva nas discussões à luz da Teoria Crítica do Currículo, visto que se trata de uma questão contemporânea em prol da democracia e da emancipação de sujeitos historicamente excluídos e estigmatizados no campo social e educacional.

Desse modo, considerando que o currículo é formulado numa variedade de áreas e níveis, fundamental para essa variedade é a distinção entre o currículo escrito e o currículo como atividade em sala de aula (GOODSON, 2011), o que aqui denominamos por "currículo vivido". Esse currículo vivido é o enfoque central de nossa pesquisa, pois compreendemos que as representações se constituem a partir da vivência deste currículo, em sala de aula, em outros ambientes educacionais, por meio das relações interpessoais nos ambientes educacionais e através das variáveis metodológicas de intervenção da prática educativa (ZABALA, 1998).

Consideramos que o currículo tem relevante papel na transformação de práticas excludentes em prol de uma cultura inclusiva. Cultura, na compreensão crítica que adotamos, não é concebida como um conjunto inerte de crenças e conhecimentos que 
são transmitidos de forma automática à próxima geração, mas sim como um campo e terreno de luta (MOREIRA; SILVA, 2011).

Nesse sentido,

[...] a tradição crítica vê o currículo como terreno de produção e criação simbólica, cultural. A educação e o currículo não atuam, nessa visão, apenas como correias transmissoras de uma cultura produzida em um outro local, por outros agentes, mas são partes integrantes e ativas de um processo de produção e criação de sentidos, de significações, de sujeitos. O currículo pode ser movimentado por intenções oficiais de transmissão de uma cultura oficial, mas o resultado nunca será o intencionado porque, precisamente, essa transmissão se dá em um contexto cultural de significação ativa dos materiais recebidos (MOREIRA; SILVA, 2011, p. 35).

Assim, a perspectiva de cultura como um campo contestado e ativo implica, para a teoria curricular crítica, que o currículo não é veículo de algo a ser transmitido e passivamente absorvido, mas o terreno no qual será ativamente produzida cultura (MOREIRA; SILVA, 2011).

Falamos em uma cultura inclusiva, pois consideramos que "[...] o currículo e as questões educacionais mais genéricas sempre estiveram atrelados à história dos conflitos de classe, raça, sexo e religião" (APPLE, 2011, p. 49). Nesse contexto dos conflitos, incluímos as questões concernentes às pessoas com deficiência e, por isso, relacionamos o currículo à diversidade e, portanto, à educação inclusiva da pessoa com deficiência, indivíduo historicamente vítima da exclusão social e educacional.

Nossa defesa por uma cultura inclusiva dá-se pelo fato de que

há na educação inclusiva a introdução de outro olhar. Uma maneira nova de se ver, ver os outros e ver a educação. Para incluir todas as pessoas, a sociedade deve ser modificada com base no entendimento de que é ela que precisa ser capaz de atender às necessidades de seus membros. Assim sendo, inclusão significa a modificação da sociedade como prérequisito para a pessoa com deficiência buscar seu desenvolvimento e exercer sua cidadania (FREITAS, 2006, p. 167). 
Desse modo, a forma como os alunos com deficiência se veem e são vistos na Universidade engendra representações multifacetadas que são expressas quando os mesmos falam sobre suas percepções e sentimentos a partir de suas vivências curriculares.

Para iniciarmos a discussão e a reflexão sobre os dados de campo, o Quadro 01, a seguir, ilustra os perfis dos mesmos, nomeando-os como A, B, C, D e E, a fim de preservar suas identidades.

\begin{tabular}{cccccc}
\hline $\begin{array}{c}\text { SUJEITO DE } \\
\text { PESQUISA }\end{array}$ & IDADE & SEXO & CURSO & PERÍODO & DEFICIÊNCIA \\
\hline A & 22 anos & Feminino & $\begin{array}{c}\text { Licenciatura em } \\
\text { História }\end{array}$ & $8^{\circ}$ semestre & Baixa visão \\
B & 24 anos & Feminino & Ciências Sociais & $1^{\circ}$ semestre & Cega \\
C & 34 anos & Feminino & Pedagogia & $6^{\circ}$ semestre & Cadeirante \\
D & 26 anos & Masculino & Letras - Língua & $8^{\circ}$ semestre & Cego \\
& & & Portuguesa & & \\
\hline E & 25 anos & Feminino & Serviço Social & $5^{\circ}$ semestre & Baixa visão \\
\hline
\end{tabular}

Quadro 01: Perfil dos sujeitos da pesquisa.

Fonte: Pesquisa de campo, 2012.

A respeito da forma de ingresso e da chegada à UFPA, apenas B ingressou por meio da política da UFPA que estabelece cotas para pessoas com deficiência, os demais ingressaram por meio de processo seletivo convencional. Quando do seu ingresso, os sujeitos de pesquisa referiram a respeito da não adoção de qualquer providência pela Instituição, por seu Instituto ou Faculdade de modo a favorecer a permanência do mesmo, conforme podemos observar nos relatos a seguir: 
Eu acho que eles nem sabiam que eu tinha entrado. Não sabiam da minha existência nem que eu tinha alguma necessidade... nem no meu cadastro, não existe nada que diga que eu sou deficiente visual. Nunca preenchi nada que indicasse isso. O que eu fiz, assim que eu cheguei, [...] foi pedir uma mesa pra eu poder utilizar o plano inclinado ${ }^{2}$ pra poder escrever. E aí eu já tinha o plano inclinado desde a escola e pedi a mesa. Foi a única coisa que fizeram por mim. (A)

Não houve uma participação assim direta, eu não vejo um interesse, uma busca pra tentar atender a minha necessidade. (E)

Infelizmente não. Já no decorrer do curso, com a minha habilidade, conseguia fazer amizade com o Instituto para que fornecesse o material, ter um diálogo legal, muitas vezes precisava pressionar mesmo, fez com que, no decorrer do curso, houvesse essa preocupação. Mas no início, todos se sentiram extremamente perdidos "como eu vou lidar com esse aluno em sala de aula?". Muitas vezes você se sentia um mero ouvinte em sala de aula, né, e você acabava não absorvendo determinados conteúdos e isso acarretava determinados prejuízos. (D)

Os excertos acima de A, D e E se referem sobre a não adoção de providência alguma, tendo eles mesmos que buscar a resolução de seus problemas, o que, mesmo assim, não significou a resolução completa dos problemas existentes, apenas estratégias parciais para possibilitar o acompanhamento das atividades educacionais.

No que se refere ao processo educacional e às vivências curriculares no âmbito dos cursos de graduação dos entrevistados, os mesmos se referiram a diversos tipos de apoio didático-pedagógico necessários para o favorecimento de suas aprendizagens, bem como ao provimento destes recursos pela Universidade, o que podemos observar nos excertos a seguir:

A fonte, no caso, tem que ser ampliada e, assim, pra uma questão de até mesmo pra ter um acesso mais rápido, porque, pra ampliar eu preciso de tempo, as pessoas que fazem esse trabalho também precisam de tempo, pra preparar o material... então, o ideal seria que tivesse disponibilizado

\footnotetext{
2 Plano inclinado é uma prancha ou porta-texto, composto de uma base sólida, que fica apoiada sobre a mesa; possui um suporte regulável, que serve para ajustar seu ângulo de inclinação, de acordo com a necessidade do aluno o que permite melhor posicionamento do tronco e da cabeça. O livro e o caderno são colocados sobre a prancha, ajudando o aluno a aproximar os olhos do material de leitura, para evitar que incline demasiada mente a cabeça sobre a carteira.
} 
umas telelupas ${ }^{3}$, que são de bolso, tem umas que ampliam até 10 vezes, só que é cara, ela custa quase 3 mil reais a melhor, então a Universidade não disponibiliza isso, eu já tentei, fiz documento, já solicitei e foi negado, até então. ( $E$ )

Assim, o apoio é fornecido pelo Espaço Braille da Biblioteca Central porque lá no meu curso ainda não tem assim. Eu diria que é essencial, é indispensável esse serviço e sem ele com certeza não daria pra terminar o curso, acho que não daria nem pra começar, não só pelos equipamentos que estão aqui, que são ótimos pra mim, mas pelas pessoas que me atendem, que tratam a gente sempre muito bem. (B)

Olha, depende bastante. Tem professores que já chegaram, já se preocuparam com isso, em ampliar a minha prova... Datashow dificilmente é ampliado... normalmente eu consigo ler só os títulos (risos)... e assim, quando eu quero ler, eu peço pra alguém ler pra mim, ou então peço depois os slides. (A)

Avalio esse oferecimento como insuficiente porque, no caso, seria eficaz se eu já chegasse em sala com o meu professor já sabendo que eu tenho a deficiência, porque isso é informado pra ele antecipado, é informada a fonte na qual eu faço a leitura, então o ideal seria se ele já chegasse na sala com o meu texto pronto, com fonte ampliada, pra que eu pudesse participar da aula igualmente como os outros alunos. (E)

Observamos, com base nos demais relatos, que o apoio fornecido pelo Espaço Braille $^{4}$ é fundamental para a contemplação das necessidades específicas ${ }^{5}$ dos alunos entrevistados, porém ainda não se mostra suficiente.

Segundo Ferreira (2006), há diversos suportes em prol da contemplação das necessidades específicas apresentadas por alunos com deficiência para a materialização de práticas inclusivas, dentre elas, destaca o oferecimento do aparato tecnológico disponível na atualidade. Desse modo, a inserção dessas tecnologias na Universidade,

3 Telelupas são instrumentos que se assemelham a um binóculo, com lentes de aumento que permitem a leitura à distância, como o letreiro de um ônibus.

${ }^{4}$ O Espaço Braille é um serviço disponibilizado na Biblioteca Central da Universidade Federal do Pará, que realiza atendimento às pessoas com deficiência visual em suas necessidades de informação. Para tanto, auxilia na leitura de documentos em tinta, pesquisas na internet, digitalização, correção de texto, digitação/formatação, impressão em tinta, impressão em Braille, conversão de arquivos e pesquisas/localização de material no acervo do SIBI (UFPA, 2011).

${ }^{5} \mathrm{O}$ conceito de necessidades específicas, aqui adotado, corresponde ao conceito expresso em Correia (2006, p. 249): “o conjunto de problemáticas relacionadas com o autismo, a deficiência mental, a deficiência auditiva, a deficiência visual, os problemas motores, as perturbações emocionais graves, os problemas de comportamento, as dificuldades de aprendizagem, os problemas de comunicação, a surdocegueira, a multideficiência e outros problemas de saúde (Aids, epilepsia, diabetes etc). 
impulsionaria o acesso desses estudantes ao conteúdo e ao aprendizado, bem como atribuiria autonomia para a ação pedagógica e curricular destes sujeitos.

A esse respeito, observamos que a não contemplação destas pela Universidade, influenciam, geralmente negativamente, a vivência do currículo pelo aluno com deficiência. A esse respeito, na perspectiva de uma educação inclusiva, Freitas (2006) pontua dois aspectos sobre os quais é necessário refletir e se apropriar. O primeiro deles é o domínio de como se dá o conhecimento do ser humano, independente de sua diversidade, nesse caso, de sua deficiência. O segundo

é o das estratégias, dos caminhos que devem ser adotados em uma escola inclusiva, para que os alunos, com suas necessidades específicas, tenham as mesmas condições de construir seu saber e desenvolver suas funções psíquicas superiores, comuns a todos os seres humanos (FREITAS, 2006, p. 174).

Ou seja, mesmo com as TICs tão presentes no cotidiano e tão disponíveis no mercado, este dado da pesquisa revela que a Universidade ainda precisa se apropriar desta realidade para assegurar um processo educacional inclusivo aos alunos com deficiência. Tal fato nos permite considerar que essas situações de desigualdade provocadas pela insuficiência do oferecimento de TICs no contexto educacional da UFPA traduzem situações de reprodução da histórica exclusão das pessoas com deficiência. Para tanto, seria primordial ampliar a oferta de recursos e serviços pelo Espaço Braille, bem como ampliar espaços como este na UFPA, de assistência e apoio didáticopedagógico ao aluno com deficiência.

Ainda sobre o provimento de recursos de apoio pedagógico ao aluno com deficiência, D afirma que

Pelo Espaço Braille, é garantido esse apoio, é um trabalho muito eficiente, você percebe no espaço que há uma impressora Braille, há o escaneamento, há computadores de bom nível para uso do deficiente visual, com internet de alta velocidade, que isso também ajuda muito na absorção da pesquisa, mas o que falta, na verdade, é o apoio do Instituto. O Instituto precisa ser parceiro do Espaço Braille, no sentido de 
viabilizar essa produção do material. Por exemplo, se eu começo uma aula no mês de março, em fevereiro já deve existir um planejamento hábil que diga "olha, tá aqui o conteúdo programático pro Espaço Braille, reproduza esse material para que o aluno consiga, já no mês de março, acompanhar". E isso seria bem tranquilo, mas não acontece isso... Mas é preciso que haja essa parceira. Antes do início das aulas, fazer um planejamento, chamar o Espaço Braille nos Institutos, reunir, chamar o aluno e dizer "olha, tá aqui o conteúdo programático, vamos produzir!" e começar as aulas logo para que esse aluno consiga ler igual aos outros. (D)

O relato de $\mathrm{D}$, permite-nos observar que a falta de articulação intrainstitucional traduz o não planejamento dos currículos que serão materializados na Universidade, o que atribui certa fragilidade a esses currículos, que ficam impossibilitados de serem implementados, no que tange à educação da pessoa com deficiência.

Por isso, é indispensável considerarmos que o currículo está no centro das relações de poder (MOREIRA; SILVA, 2011). Esse poder arraigado ao currículo é expresso pelas constantes disputas (ARROYO, 2011) no campo de sua materialização. No que tange ao currículo na perspectiva da inclusão, outras disputas de igual magnitude estão imbricadas, visto que o conhecimento disposto no currículo deve ser em conformidade com os interesses das classes dominantes, ou seja, contra os alunos com deficiência, que correspondem ao segmento historicamente excluído dos contextos social e educacional.

Para que o currículo possa ser instrumento de resistência e emancipação diante dos conflitos e disputas por poder, faz-se necessária uma articulação intrainstitucional de modo a implementar ações que favoreçam, aos alunos com deficiência, a vivências dos currículos, garantindo o acesso aos mesmos e o acompanhamento das atividades previstas.

No contexto das variáveis metodológicas de intervenção ${ }^{6}$ (ZABALA, 1998), os sujeitos de pesquisa referiram, a respeito do planejamento das aulas e da seleção de conteúdos, que seus professores pouco levavam em consideração a sua presença em sala

\footnotetext{
${ }^{6}$ Para Zabala (1998, p. 18), as variáveis metodológicas de intervenção da prática educativa são "um conjunto de atividades ordenadas, estruturadas e articuladas para a realização de certos objetivos educacionais, que têm um princípio e um fim conhecidos tanto pelos professores como pelos alunos". As variáveis metodológicas de intervenção abordadas neste estudo foram a forma de organização da sala de aula, o planejamento das aulas, a seleção dos conteúdos, as metodologias de ensino adotadas, os recursos didáticos utilizados e o processo avaliativo.
} 
de aula, enquanto aluno com deficiência, tal como podemos observar nos excertos a seguir:

Acho que leva bem pouco em consideração. Como eu te disse, a maioria das metodologias são essas: ler o texto e trabalhar o texto na aula. Quando eu não tinha o CCTV ${ }^{7}$ portátil, se o professor fosse ler algum parágrafo na aula, ou alguma coisa, eu ficava só ouvindo, ou então quando era pra ler na hora, alguém tinha que ler pra mim. Então são situações que não se pensa que eu não vou poder ler, por exemplo. (A)

Você pega um início de aula, com um material didático diverso pra ser lido, você passa 15 dias pra ler, enquanto o aluno que enxerga lê em tempo hábil. Então esses 15 dias já são um prejuízo considerável para que a pessoa com deficiência tenha acesso a isso. (D)

A maioria dos professores sim, mas teve um episódio numa disciplina que, tipo, a professora não levou muito em consideração que tinha uma aluna com deficiência visual na sala. Ela colocou um documentário em alemão e sem dublagem, só na legenda, eu me senti super excluída. (B)

Uma parcela pouco significativa, sim... eu creio que alguns professores possuíam sensibilidade, no sentido de conversar, de vir ao Espaço Braille, conversar sobre o conteúdo programático, mas na maioria, num termo bem vulgar, era "te vira", tipo, se você foi capaz de chegar até a Universidade, você já é capaz de se virar, de conseguir o seu espaço. Só que, com o tempo, com minha persistência, isso foi melhorando. (D)

A gente percebe que ainda há uma certa fragilidade, assim, porque os professores, eles não percebem... alguns, por já terem tido alunos com deficiência visual, têm aquela experiência, tipo já fica mais aberto a como esse deficiente visual vai se sentir, como vai preferir ter acesso ao material, outros não sabem nem o que fazer... (E)

Observamos que os relatos a respeito da materialização das práticas em sala de aula traduzem situações de exclusão e desigualdade. Uma educação inclusiva pressupõe mudanças legais, curriculares, avaliativas, de planejamento e de representações sobre os sujeitos a serem incluídos no processo.

\footnotetext{
${ }^{7}$ CCTV é um circuito fechado de televisão, aparelho acoplado a um monitor de TV monocromático ou colorido que amplia até 60 vezes as imagens e as transfere para o monitor. O CCTV portátil possui um visor menor, mas com ampla capacidade de aumento e pode ser facilmente transportado.
} 
Segundo Correia (2006), a educação especial, ou melhor, os serviços de educação especial necessitam ser um dos pilares essenciais em que se deve assentar o ensino para os alunos com deficiência. Isso significa, para este autor, que a educação especial não deve ser um lugar, mas sim um conjunto de serviços e apoios especializados a que o aluno com deficiência tem direito e que a instituição educacional deve prover a quem necessitar.

Observamos que a realidade evidenciada pelas falas dos sujeitos de pesquisa não estão em consonância com o dever institucional de prover a formação dos professores e as ajudas técnicas de acordo com as necessidades específicas dos alunos.

Sobre as metodologias de ensino e recursos didáticos adotados pelos professores dos alunos com deficiência, os sujeitos de pesquisa também foram questionados se os docentes pensavam em metodologias e recursos acessíveis, de acordo com suas necessidades específicas. Uma das resposta diz que:

Infelizmente não porque, filmes, por exemplo, muitas vezes eram legendados aí quando eu reclamava, dizia "ah não, não assiste o filme, tá liberado hoje, vou ver se eu dublo o filme e passo pra ti" e aí acabava não passando... livros, como eu falei, tinha que trazer pro Espaço Braille pra produzir, muitas vezes o livro nem havia aqui, aí a funcionária tinha que ir lá na biblioteca do mestrado pra ver se conseguia o livro. Então foi uma tarefa muito árdua mesmo, mas assim, houve alguma tentativa de melhora, mas devido ao baixo nível de material tecnológico, acabava que a coisa não acontecia a contento, justamente porque uma grande dificuldade que eu gostaria de relatar, além da falta de compreensão do professor, a maioria da turma acabava não me incluindo, porque, veja, você enxerga e tem um tempo pra fazer a leitura, você tem um prazo. Por que você vai esperar um cego por quinze dias pra que ele possa ler o material como você? "Esse cego tá com malandragem! Ele não quer estudar! Porque, pô, ele fica de cabeça baixa na sala de aula, ele só ouve a explicação do professor! Então ele não estuda!". Então, passei por isso também. (D)

$O$ relato de $D$ expressa o menosprezo às potencialidades da pessoa com deficiência e a não compreensão das necessidades apresentadas pela pessoa cega. Mas D não foi o único sujeito de pesquisa que referiu não haver planejamento de metodologias e recursos acessíveis para os alunos com deficiência, como podemos ver nos excertos a seguir: 
Não, eu acho que não! (risos) Eu acho assim, talvez, se eu tivesse, desde o início do curso apresentado maiores demandas, eles tivessem começado a se tocar e tivessem modificado alguma coisa. Mas eu acho que eu talvez tenha mal acostumado eles, porque aí eles partiam do princípio de "ah não, ela se vira, ela dá o jeito dela". [...] eu faço curso de licenciatura e a própria formação pra lidar com o aluno com alguma deficiência é muito escassa e a gente discute isso, mas eu acho que a minha presença gerou esse tipo de discussão. Então isso é bem interessante. Na primeira disciplina que eu fiz, que foi a do professor que mais deu atenção, isso foi uma coisa bem discutida e depois, em projetos que ele desempenhou ele colocou essa questão, depois ele até me convidou pra fazer parte de discussões nesse sentido em outras turmas. Então eu acho que a minha presença pode ter gerado essa mudança, o fato da pessoa se propor a discutir um tema que os professores não tinham conhecimento, que eles mesmos falavam "não tenho formação", entendeu? Talvez eu seja a primeira aluna com deficiência que eles tenham encontrado na Universidade, né... talvez, pelo menos que eu saiba... ninguém me falou de outro aluno. Então eu penso que talvez eles tenham prestado atenção nisso, né... (A)

É, teve alguns momentos, principalmente em prova, porque texto que é o maior recurso, cada um tira o seu, é a gente que providencia. Mas às vezes, quando eles iam levar uma atividade, um mapa, um documento, tiveram, assim, três professores que eu me lembre que se preocuparam em levar ampliado, o que era até uma surpresa pra mim, né! Ver um professor com material ampliado. A minha orientadora sempre levava tudo ampliado, até o programa da disciplina ela levava ampliado. Por ser próximo, o marido dela, que também foi meu professor, também começou a levar tudo ampliado (risos). E mais uns dois que se preocuparam com isso. (A)

Os relatos de $A$ indicam que poucos professores pensavam na questão da acessibilidade destes recursos e metodologias às deficiências dos alunos. Apesar disso, podemos observar que a presença deste aluno com deficiência em sala de aula, por si só, provocou alguma formação para os professores, os quais passaram a pensar a respeito dessas adequações nas vivências cotidianas.

É importante ressaltar que compreendemos a formação de professores como um processo contínuo e inacabado que visa o aperfeiçoamento da prática educativa, com vistas ao desenvolvimento do processo ensino/aprendizagem. Nessa perspectiva, concebemos a formação de professores enquanto a área de conhecimento, investigação e propostas teóricas e práticas que se destinam a estudar as dinâmicas nas quais os 
professores se envolvem individualmente ou em equipe, assim como experiências de aprendizagem que servem de base para aquisição e aprimoramento de conhecimentos, desenvolvimento de competências ou disposições, objetivando elevar a qualidade da educação que os alunos recebem (GARCíA, 1999).

Nesse contexto, Denari (2006) ressalta o descompasso entre a formação inicial de professores e as exigências da educação inclusiva, concebendo a necessidade da realização de ajustes curriculares de acordo com os diferentes enfoques e as necessidades operativas assumidas, com ênfase na proposta de uma educação inclusiva. Esses ajustes devem ter por objetivo dotar os futuros profissionais dos elementos teóricos, metodológicos e técnicos necessários ao desenvolvimento de uma prática profissional exitosa, ou seja, efetivamente inclusiva.

Ainda a respeito dos currículos dos cursos de formação inicial de professores, Denari (2006) considera que o mesmo deve conter delineamentos específicos de modo a favorecer a formação dos futuros docentes, contemplando a necessária articulação metodológica e didática para a intervenção e o planejamento de ações de caráter formativo, ou seja, na formação do professor seria importante prever, inicialmente, um preparo de efetiva qualidade para lidar com a diversidade, além de formação específica em educação especial, para prover os apoios pedagógicos previstos na legislação.

Dessa forma, pensamos ser fundamental, tanto na formação inicial quanto na continuada, proporcionar aos professores em formação os conhecimentos básicos para uma prática inclusiva (FREITAS, 2006).

A respeito do processo de avaliação adotado pelos professores, os alunos referiram a luta por condições adequadas de realização das avaliações, tal como podemos observar nos excertos a seguir:

Já houve o caso de uma professora me propor uma avaliação... no caso assim, ela me deixou aberta pra dizer como eu queria ser avaliada, nesse sentido. E aí eu recusei porque eu disse que eu queria ser avaliada como os outros alunos, né, fazer os trabalhos, provas, que se eu demorasse um pouco mais, aí eu contava com a compreensão dela, né, de eu demorar um pouco mais pra entregar... (E) 


\begin{abstract}
Olha, nesse sentido houve uma resistência muito grande porque eu sempre fui acostumado, no decorrer do meu ensino fundamental e médio, a fazer a prova junto com os outros alunos. E aqui no nível superior eu sempre tive que fazer prova sozinho aqui no Espaço Braille e isso no início foi um pouco constrangedor pra mim porque é aquilo... o quê que o professor deve tá pensando de mim? Que eu tô colando na prova? Que eu tô fazendo isso ou aquilo... mas aí depois eu fui começando a entender que, como não havia um planejamento, eu tinha que passar por isso, mas a minha vontade era a de fazer prova na sala mesmo em Braille, mas ao mesmo tempo eu sabia que a máquina podia atrapalhar os outros alunos por causa do barulho, aí eu fui aceitando essa coisa de fazer a prova sozinho em outro lugar. Mas eles buscavam trazer a prova assim, no dia da prova mesmo. Às vezes eu chegava aqui com a funcionária e dizia "hoje tem prova nove e meia da manhã", mas já era nove horas e ela perguntava "mas cadê o professor?", aí ele nem trazia, vinha trazer só no outro dia, mas eu sempre fazia a prova aqui no Espaço Braille, sempre havia esse espaço cedido. Mas o professor deixava às vezes muito pra cima da hora, achava que era uma coisa simples, fazer uma prova em Braille porque pensava "ah, é só uma folhinha, é só scanear", mas não é assim, às vezes tem um gráfico ou algo mais complexo, mas conseguimos, aqui com esse apoio do Espaço Braille, sanar essas dificuldades e fazer a prova também num lugar tranquilo com bastante concentração, sem ninguém te pressionando por causa de fim de horário de prova. (D)
\end{abstract}

Observamos nos relatos de D e E propostas de avaliação facilitada, o que, a nosso ver, menosprezam o potencial do aluno com deficiência, pois, apesar de prevista na legislação, adaptação curricular ou de avaliação no compete facilitar esse processo, mas sim oferecer condições acessíveis para que a pessoa com deficiência possam expressar seus conhecimentos acadêmicos.

Essas propostas traduzem representações docentes de menosprezo à capacidade da pessoa com deficiência, bem como de descaso com a formação competente e compromissada desse aluno por esse professor. Apesar disso, observamos que os alunos com deficiência consideravam favorável quando o professor buscava uma forma adequada de avaliá-los, sem, com isso, facilitar esta avaliação.

Desse modo, a avaliação torna-se, também, uma expressão do poder, visto que ainda se parte "do princípio de que as aprendizagens estabelecidas no currículo precisam ser cumpridas, e de que a avaliação permitirá identificar quem consegue ou não atingir as 
metas estabelecidas" (CORTESÃO, 2006, p. 123). Nessa situação é expresso, também, o “poder de constranger", tal como denomina Cortesão (2006, p. 125), o qual "é característico de situações em que o poder é exercido indiretamente, e a distância, por toda uma forma de organização socioeconômica cada vez mais informada por orientações neoliberais".

Ou seja, as relações de poder acabam por interferir nesse oferecimento de oportunidades aos alunos com deficiência, conduzindo-os ao risco do insucesso acadêmico por razões externas às suas potencialidades, mas sim por conta da falta do aparato necessário para a externalização dessas potencialidades.

\section{À guisa de conclusão}

Acreditamos, com base nos resultados explanados, que a efetivação de práticas inclusivas na Universidade Federal do Pará ainda é caminho que vem sendo trilhado, como qualquer processo histórico e social.

Observamos, por meio dos estudos apresentados que versam sobre a educação inclusiva no ensino superior, que esta ainda é discreta, quando comparada aos casos de educação inclusiva na educação básica, o que pode ser reforçado pelas normativas mencionadas, que enfatizam objetivamente a educação inclusiva neste nível educacional.

Confrontando as normativas nacionais com as normativas institucionais da UFPA, podemos observar o atendimento às discretas prescrições oficiais, porém reiterando que algumas prescrições são contempladas, porém apenas como previsão. Ou seja, ainda não se encontram efetivadas, mas já se encontram mencionadas enquanto necessidades e metas a serem alcançadas a curto, médio e longo prazo. Isso já se constitui como indicativo de que esta Universidade sabe acerca das necessidades institucionais e objetiva contemplá-las.

O movimento da pesquisa de campo ocorreu em meio a diversos entraves no âmbito institucional, por isso, faz-se relevante pontuar que a estrutura e os serviços do Espaço Braille foram porta de entrada da pesquisa junto aos sujeitos de pesquisa, e é 
indispensável reconhecer a importância deste setor no que tange à facilitação da educação inclusiva na UFPA.

Porém, do mesmo modo, justamente pela importância que o mesmo assume diante da implementação da educação inclusiva nesta Universidade, as ações, os serviços e o próprio espaço físico deste necessita ser ampliado, de modo a comportar e contemplar a extensa demanda existente em tempo hábil, para favorecer o acompanhamento igualitário das aulas e atividades curriculares pelos alunos com deficiência visual na UFPA.

A abordagem materialista-histórica e dialética facilitou a compreensão das representações nesse campo de disputas que é o currículo. Percebemos que a materialização do currículo é transversalizada pelas tecnologias, que são capazes e promover e, muitas vezes, permitir o acesso ao currículo pelo aluno com deficiência.

Concebemos que a presente pesquisa favoreceu a ampliação de nosso arcabouço teórico e científico no âmbito da educação inclusiva, das vivências, dos movimentos sociais, da educação superior e do trato com a diversidade, contribuindo inquestionavelmente para o amadurecimento técnico e científico de nossa postura enquanto profissionais e pesquisadores nesse campo de estudo.

Podemos, então, considerar que a vivência do currículo traz consigo nuances que só podem ser alcançadas por meio do conhecimento das realidades dos sujeitos sociais envolvidos no processo. Tais realidades, quando relatadas e registradas, podem nos auxiliar a compreender problemáticas atuais e pensar mecanismos estratégias para superação de adversidades e efetivação do ideário inclusivo.

\section{Referências}

ALCOBA, Susie de Araújo Campos. A inclusão de alunos com deficiência na universidade: o desafio pedagógico. [20--]. Disponível em:

<http://www.sociedadeinclusiva.pucminas.br/Vseminario/Anais_V_Seminario/educacao/c omu/A\%2OINCLUSAO\%20DE\%20ALUNOS\%20COM\%20DEFICIENCIA\%20NA\%20UNIVERSIDAD E\%20-\%20O\%20DESAFIO\%2OPEDAGOGICO.pdf>. Acesso em 27 de agosto de 2011, às 16:56h. 
APPLE, Michael Whitman Repensando o currículo. In: MOREIRA, Antônio F.; SILVA, Tomaz T. (Orgs.). Currículo, cultura e sociedade. 12. ed. São Paulo: Cortez, 2011. p. 49-69.

ARROYO, Miguel Gonzáles. Currículo, território em disputa. Petrópolis, RJ: Vozes, 2011.

BARDIN, Lawrence. Análise de conteúdo. Lisboa: Edições 70, 1979.

BRASIL. Ministérios da Educação. Programa vai incluir portador de deficiência no ensino superior. Brasil, 2005. Disponível em:

<http://portal.mec.gov.br/index.php?option=com_content\&view=article\&id=2985\&catid= 212>. Acesso em 27 de agosto de 2011, às 11:36h.

CORREIA, Luis de Miranda. Dez anos de Salamanca, Portugal e os alunos com necessidades educativas especiais. In: RODRIGUES; David (Org.). Inclusão e educação: doze olhares sobre a educação inclusiva. São Paulo: Summus, 2006. p.239-274.

CORTESÃO, Luiza. O arco-íris e o fio da navalha - problemas da educação em face das diferenças: um olhar crítico, uma proposta de análise. In: RODRIGUES. David (Org.). Inclusão e educação: doze olhares sobre a educação inclusiva. São Paulo: Summus, 2006. p.115-140.

DENARI, Fátima. Um (novo) olhar sobre a formação do professor de educação especial: da segregação à inclusão. In: RODRIGUES, David (Org.). Inclusão e educação: doze olhares sobre a educação inclusiva. São Paulo: Summus, 2006. p. 35-63.

FERREIRA, Julio Romero. Educação especial, inclusão e política educacional: notas brasileiras. In: RODRIGUES. David (Org.). Inclusão e educação: doze olhares sobre a educação inclusiva. São Paulo: Summus, 2006. p. 85-113.

FRANCO, Maria Laura. Análise do conteúdo. 3. ed. Série Pesquisa. Brasília: Liber Livro Editora, 2008.

FREITAS, Soraia Napoleão. A formação de professores na educação inclusiva: construindo a base de todo o processo. In: RODRIGUES. David (Org.). Inclusão e educação: doze olhares sobre a educação inclusiva. São Paulo: Summus, 2006. p.161-181.

GARCÍA, Carlos Marcelo. Formação de professores: para uma mudança educativa. Portugal: Porto Editora, 1999.

GOODSON, Ivor. Currículo: teoria e história. 11. ed. Petrópolis: Vozes, 2011.

IBGE - Instituto Brasileiro de Geografia e Estatística. Censo demográfico 2010. Resultados Preliminares da Amostra. Brasília, 2011. 
MINAYO, Maria Cecília et al. Pesquisa social: teoria, método e criatividade. Petrópolis: Vozes, 1994.

MOREIRA, Antônio Flávio.; SILVA, Tomaz Tadeu da. Sociologia e teoria crítica do currículo: uma introdução. In: MOREIRA, Antônio F.; SILVA, Tomaz T. (Orgs.). Currículo, cultura e sociedade. 12 ed. São Paulo: Cortez, 2011. p. 13-47.

PESSINI, Maria Adelaide; SILVA, Renata; SILVA, Vinicius. Compreendendo as experiências dos alunos com necessidades especiais no ensino superior. Akropólis, Umuarama, v. 15, n. 1 e 2, p. 19-24, jan./jun. 2007.

PIRES, Marília Freitas de Campos. O método materialista histórico-dialético e a educação. Interface - Comunicação, Saúde, Educação, v.1, n.1, 1997.p.83-92

SACRISTÁN, Gimeno. O currículo: uma reflexão sobre a prática. Porto Alegre: ArtMed, 1998.

SACRISTÁN, Gimeno. O currículo: uma reflexão sobre a prática. Porto Alegre: Artmed, 2000.

SEVERINO, Antônio Joaquim. Metodologia do trabalho científico. 23. ed. São Paulo,:Cortez, 2007.

TRIVIÑOS, Augusto Nibaldo Sila. Introdução à pesquisa em ciências sociais: a pesquisa qualitativa em educação. São Paulo: Atlas, 1987.

TRIVIÑOS, Augusto Nibaldo Silva. Introdução à pesquisa em ciências sociais: a pesquisa qualitativa em educação. 3 ed. São Paulo: Atlas, 2011.

UNIVERSIDADE FEDERAL DO PARÁ. PRÓ-REITORIA DE PLANEJAMENTO E DESENVOLVIMENTO INSTITUCIONAL. Plano de desenvolvimento institucional 2011-2015. 2011.

ZABALA, Antoni. A prática educativa: como ensinar. Porto Alegre: ArtMed, 1998.

Recebido em: 04/10/2013 Aprovado em: 17/03/2014

Universidade do Estado de Santa Catarina - UDESC Programa de Pós-Graduação em Educação - PPGE 